\title{
PENGARUH KEDISIPLINAN DAN KENYAMANAN TARUNA/ TARUNI DI ASRAMA KAMPUS AKPELNI TERHADAP HASIL PEMBELAJARAN
}

\author{
Evyana Diah Kusumawati, MA $^{1)}$ \\ 1)Akademi Pelayaran Niaga Indonesia Semarang \\ Email:kusuma1002@yahoo.co.id
}

\begin{abstract}
Abstrak
Penelitian ini bertujuan untuk mengetahui (1) seberapa besar pengaruh kedisiplinan taruna/ taruni terhadap hasil pembelajaran, (2) seberapa besar pengaruh kenyamanan taruna/ taruni di asrama kampus Akpelni terhadap hasil pembelajaran, (3) faktor pendukung dan penghambat kedisiplinan taruna/ taruni dalam meningkatkan hasil pembelajaran.

Populasi dalam penelitian ini adalah taruna/ taruni angkatan 51 dan 52 dengan jumlah 1080 orang. Pengumpulan data dengan metode kuesioner untuk mengumpulkan data Kedisiplinan dan Kenyamanan di Asrama kampus Akpelni, sedangkan metode dokumentasi untuk mengetahui Hasil pembelajaran. Uji coba instrumen ini dilakukan terhadap 92 taruna/taruni angkatan 51 dan 52 prodi KPN, Nautika dan Teknika, analisis data yang digunakan adalah teknik analisis regresi ganda. Sebelum analisis data terlebih dahulu diadakan pengujian persyaratan analisis meliputi uji Normalitas, Heterokedastisitas dan Autokorelasi.

Hasil penelitian ini adalah: (1) Terdapat pengaruh kedisiplinan terhadap hasil pembelajaran yang ditunjukkan dengan nilai t hitung lebih besar dari $t$ tabel yaitu: 2,900 > 1,987 dengan koefisien determinasi sebesar 0,165 yang artinya sebesar $1,65 \%$ variabel ini mempengaruhi hasil pembelajaran. (2) Terdapat pengaruh kenyamanan di asrama kampus Akpelni terhadap hasil pembelajaran yang ditunjukkan dengan nilai thitung lebih besar dari t tabel yaitu: $1,987<2,834>-1,987$ dengan koefisien determinasi sebesar 0,165 yang artinya sebesar $1,65 \%$ variabel ini mempengaruhi hasil pembelajaran. (3) faktor pendukung dan penghambat kedisiplinan taruna/ taruni dalam meningkatkan hasil pembelajaran adalah tujuan/ kurikulum, lingkungan kampus, siswa (taruna/ taruni) dan sikap dosen. Persamaan garis regresi ganda $\mathrm{Y}=$ $100,698+0,689 \times 1+1,082 \times 2$.
\end{abstract}

Kata Kunci : Kedisiplinan, Kenyamanan di asrama dan Hasil Pembelajaran,

\section{Abstract}

This study aims to determine (1) how big the influence of taruna/ taruni discipline on learning outcomes, (2) how much influence the comfort of taruna/ taruni in Akpelni campus dormitory towards learning outcomes, (3) supporting factors and inhibiting discipline of taruna/ taruni in improving learning outcomes.

Population in this research is tarunal taruni force 51 and 52 with amount of 1080 persons. Data collecting by questionnaire method to collect data of 
Discipline and Convenience in Akpelni campus dormitory, while documentation method to know learning result.

The test of this instrument was conducted on 92 taruna/ taruni force 51 and 52 study program of KPN, Nautika and Teknika, data analysis used is multiple regression analysis technique. Prior to the analysis of data in advance held testing requirements analysis include test Normality, Heterokedastisitas and Autokorelasi.

The results of this research are: (1) There is influence of discipline to result of learning which is indicated by $t$ value count bigger than t table that is: 2,900> 1,987 with coefficient of determination equal to 0,165 which mean equal to 1,65\% this variable influence result of learning. (2) There is influence of comfort at campus Akpelni campus to result of learning which is indicated by $t$ value count bigger than t table that is: 1,987<2,834> -1,987 with coefficient of determination equal to 0,165 which mean equal to $1,65 \%$ this variable influence result of learning. (3) supporting factors and discipline of cadets / taruni in improving learning outcomes are the objectives/ curriculum, campus environment, students (taruna/ taruni) and the attitude of lecturers. The equation of multiple regression lines $Y=100.698+0.689 X 1+1.082 X 2$.

Keywords: Discipline, Leisure in the dormitory and Learning Outcomes,

\section{PENDAHULUAN}

Pendidikan merupakan proses pembentukan diri manusia secara menyeluruh, bukan hanya sekedar mentransfer ilmu pengetahuan tetapi mengupayakan bagaimana agar menjadi manusia yang bermoral baik, mandiri, tanggung jawab serta mampu menghadapi kehidupan dengan tetap bijaksana. Di Indonesia, pendidikan diselenggarakan dalam dua bentuk, yaitu pendidikan formal dan pendidikan non formal (Nur Salim,2010:1).

Pendidikan merupakan suatu sistem yang terdiri dari input, proses, dan output. Input merupakan peserta didik yang akan melaksanakan aktivitas belajar, proses merupakan kegiatan dari belajar mengajar, sedangkan output merupakan hasil dari proses belajar. Berhasil atau tidaknya dari proses pembelajaran dapat dilihat dari hasil proses itu sendiri melalui berbagai penilaian, salah satu penilaian untuk mengukur berhasil tidaknya sebuah proses pembelajaran yaitu dengan melihat prestasi belajar.

Kedisiplinan merupakan salah satu sikap atau perilaku yang harus dimiliki oleh siswa. Siswa akan memperoleh hasil pembelajaran yang memuaskan apabila siswa dapat mengatur waktu dan kegiatan belajarnya. Pencapaian pembelajaran yang baik selain karena adanya tingkatan kecerdasan yang cukup, baik, dan sangat baik, juga didukung adanya disiplin sekolah yang ketat dan konsisten, disiplin individu dalam belajar, dan juga karena perilaku yang baik. Untuk membina kemadirian dan kedisiplinan, sekolah berasrama khususnya yang berlandaskan pada kedisiplinan semi militer, seringkali memiliki karakteristik yang berbeda dibandingkan dengan sekolah- 
sekolah lainnya. Karakteristik tersebut diantaranya adalah tuntutan yang dihadapi dalam kegiatan akademis, kegiatan fisik dan komunikasi antar siswa/i dengan kakak tingkatnya serta banyaknya peraturan yang harus diikuti dibandingkan dengan sekolah umum lainnya. Berdasarkan latar belakang diatas maka permasalahan yang dapat dirumuskan adalah seberapa besar pengaruh kedisiplinan taruna/ taruni terhadap hasil pembelajaran, seberapa besar pengaruh kenyamanan taruna/ taruni di asrama kampus Akpelni terhadap hasil pembelajaran dan faktor apa saja pendukung dan penghambat kedisiplinan taruna/ taruni dalam meningkatkan hasil pembelajaran.

\section{METODOLOGI PENELITIAN Jenis Penelitian}

Metodologi yang digunakan dalam penelitian ini adalah metode kuantitatif dengan mengkaji hubungan antara kedisiplinan taruna/ taruni dan kenyamanan di asrama kampus Akpelni terhadap hasil pembelajaran.

Rancangan penelitian dapat digambar sebagai berikut :

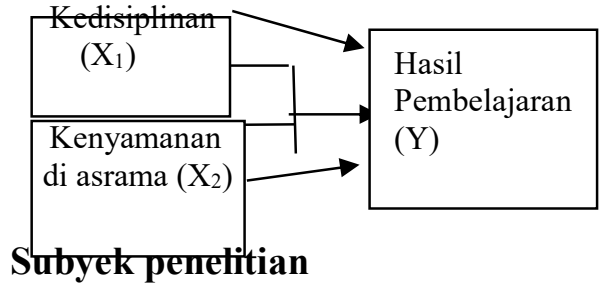

Populasi target dalam penelitian ini adalah taruna/ taruni Akpelni Semarang, sedangkan populasi terjangkau adalah taruni/ taruni Akpelni Semarang angkatan 51 dan 52 sebanyak 92 responden.

Teknik pengumpulan data.
Menggunakan kuisioner dan dokumentasi. Pengambilan sampel menggunakan teknik sampel acak terstratifikasi (stratified random sampling),

Penentuan jumlah sampel menggunakan rumusan (Bungin, 2009), sebagai berikut:

$$
\begin{aligned}
& \mathrm{n}=\frac{\mathrm{N}}{\mathrm{N} \cdot \mathrm{d}^{2}+1} \\
& \mathrm{n}=\text { Ukuransampel } \\
& \mathrm{N}=\text { Ukuran populasi } \\
& \mathrm{d}=\text { Nilai presisi (ditentukan, yaitu }
\end{aligned}
$$

$90 \%$ atau $a=0,01$ )

\section{Analisis Data}

Analisis data yang digunakan adalah analisis regresi ganda.

a. Model Analisis

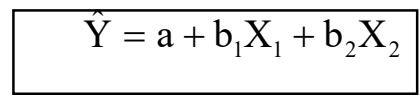

Hipotesis Statistik

Uji Signifikansi Persamaan Regresi Ganda

a. Uji Signifikan Parameter Regresi Ganda

Dimana $\beta$ adalah koefisien regresi dan $\mathrm{j}$ adalah variable $\mathrm{X}_{1}$ dan $\mathrm{X}_{2}$

b. Uji Individual Parameter Regresi ganda

\section{Uji Sigifikansi Korelasi}

a. Uji Signifikansi Koefisien Korelasi Ganda, dimana $\rho$ adalah korelasi

b. Uji Signifikansi Korelasi Parsial

1) Korelasi $Y$ dengan $X 1$

2) Korelasi $Y$ dengan $X 2$

Prosedur pengujian dengan uji t sebagai berikut:

1. Menentukan hipotesis nol dan hipotesis alternatif

Ho $: \mathrm{b}=0 \quad$ (kedisiplinan dan kenyaman secara parsial tidak berpengaruh terhadap Hasil belajar).

$\mathrm{Ha}: \mathrm{b} \neq 0 \quad$ (kedisiplinan dan kenyaman ssecara parsial berpengaruh terhadap Hasil belajar). 
2. Menentukan $t$ tabel dengan menggunakan tingkat signifikansi 0,05 pada $\mathrm{df}=\mathrm{n}-\mathrm{k}-1$ atau $92-2-1=$ 89 (k adalah jumlah variable independen), dengan uji 2 sisi diperoleh hasil $\mathrm{t}$ table $=1,662 /$ 1,662

3. Kriteria pengujian

- Ho diterima bila - $t$ hitung $\geq$ - $t$ tabel atau $\mathrm{t}$ hitung $\leq \mathrm{t}$ tabel

- Ho ditolak bila -t hitung $<-t$ tabel atau $t$ hitung $>\mathrm{t}$ tabel

\section{HASIL PENELITIAN \\ PEMBAHASAN \\ HASIL PENGUKURAN \\ Uji Normalitas}

Untuk memeriksa kenormalan dapat digunakan uji Kolmogorov-Smirnov yaitu dengan membandingkan Pvalue statistic Kolmogorov-Smirnov dengan $\alpha=0,05$

\section{Grafik uji Kolmogorov-Smirnov}

D

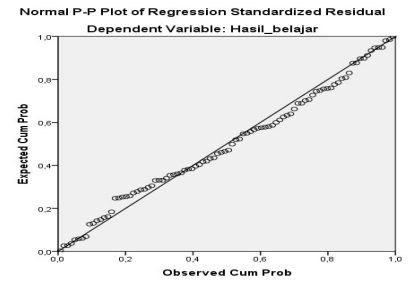

bahwa titik-titik menyebar sekitar garis dan mengikuti garis diagonal, maka model regresi tersebut telah normal dan layak dipakai untuk memprediksi variabel bebas.

\section{Uji Heteroskedastisitas}

Tabel Koefisien

(Heteroskedastisitas)

Uji Heteroskedastisitas

\begin{tabular}{|c|c|c|c|}
\hline \multirow{2}{*}{\multicolumn{2}{|c|}{ Model }} & \multicolumn{2}{|c|}{ Collinearity Statistics } \\
\hline & & Tolerance & VIF \\
\hline \multirow[t]{2}{*}{1} & (Constant) & & \\
\hline & Kedisiplinan & 0,996 & 1,004 \\
\hline
\end{tabular}

Pada tahap ini, untuk mengetahuinya digunakan uji Glejser. Apabila ditemukan kasus heteroskedastisitas maka solusinya adalah melakukan transformasi terhadap variable.

\section{Grafik Uji Heteroskedastisitas}

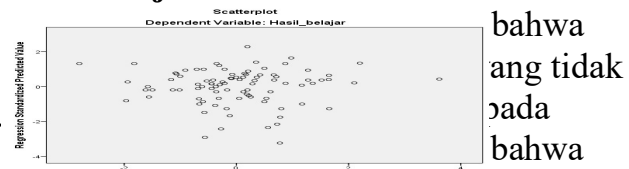

ııак terjaаı masaian neterokeaastisitas pada model regresi.

Tabel Nilai signifikant Coefficients $^{\mathrm{a}}$

\begin{tabular}{|l|l|c|}
\hline \multicolumn{2}{|c|}{ Model } & \\
\multicolumn{2}{|c|}{} & \\
\hline \multirow{2}{|c|}{1} & (Constant) & Sig. \\
\cline { 2 - 3 } & Kedisiplinan & 0,000 \\
\cline { 2 - 3 } & Kenyamanan & 0,005 \\
\hline \multicolumn{2}{|c|}{$\begin{array}{l}\text { a.Dependent Variable } \\
\text { Pembelajaran }\end{array}$} & $: 006$ \\
\hline
\end{tabular}

Pada tabel Nilai signifikant lebih besar dari 0,05. Jadi dapat disimpulkan bahwa tidak terjadi masalah heterokedastisitas pada model regresi.

\section{Uji Autokorelasi}

Pada tahap ini uji yang digunakan adalah uji Durbin Watson,

\section{Tabel Durbin Watson}

\begin{tabular}{|l|l|}
\hline \multicolumn{2}{|c|}{ Model Summary $^{\text {b }}$} \\
\hline Model & $\begin{array}{l}\text { Durbin- } \\
\text { Watson }\end{array}$ \\
\hline 1 & 2,295 \\
\hline
\end{tabular}

\section{a. Predictors: (Constant), Kenyamanan, Kedisiplinan b. Dependent Variable: Res_2}

Dapat

diketahui bahwa nilai Durbin Watson sebesar 2,295 Sedangkan dari tabel DW dengan signifikansi 0,05 dan jumlah data $(\mathrm{n})=92$, serta $\mathrm{k}=2(\mathrm{k}$ adalah jumlah variabel independen) diperoleh nilai $\mathrm{dl}$ sebesar 1,61656 dan du sebesar 1,70526. Karena nilai DW 2,295 lebih besar dari nilai du disimpulkan bahwa tidak terjadi masalah autokorelasi. 
METODE ANALISIS

Uji Signifikansi Persamaan Regresi Ganda

Tabel Hasil koefisien Analisa regresi ganda

\begin{tabular}{|c|c|c|c|}
\hline \multirow{2}{*}{\multicolumn{2}{|c|}{ Model }} & \multicolumn{2}{|c|}{$\begin{array}{l}\text { Unstandardized } \\
\text { Coefficients }\end{array}$} \\
\hline & & B & $\begin{array}{l}\text { Std. } \\
\text { Error }\end{array}$ \\
\hline 1 & (Constant) & 100,698 & $\begin{array}{c}8, \\
593\end{array}$ \\
\hline & Kedisiplinan & 0,689 & 0,238 \\
\hline & Kenyamanan & 1,082 & 0,382 \\
\hline
\end{tabular}

Persamaan regresinya sebagai berikut:

$\hat{\mathrm{Y}}=\mathrm{a}+\mathrm{b}_{1} \mathrm{X}_{1}+\mathrm{b}_{2} \mathrm{X}_{2}$

$\hat{Y}=100,698+0,689 X_{1}+1,082 X_{2}$

Constant $100,698=$ Jika Kedisiplinan dan kenyamanan nilainya adalah 0 , maka hasil pembelajaran nilainya sama dengan 100,698. Sedangkan nilai koefisien $\mathrm{X}_{1}$ sebesar 0,689 yang artinya, apabila nilai Kedisiplinan $\left(\mathrm{X}_{1}\right)$ meningkat 1 poin maka nilai Hasil Pembelajaran (Y) akan meningkat pula sebesar 0,744 poin, dengan asumsi $\mathrm{X}_{2}$ tetap. Sedangkan koefisien $\mathrm{X}_{2}$ sebesar 1,082 artinya apabila Kenyamanan di asrama $\left(\mathrm{X}_{2}\right)$ meningkat 1 poin maka pertambahan nilai pada Hasil Pembelajaran (Y) sebesar 1,082 poin pula, dengan asumsi $\mathrm{X}_{1}$ tetap.

\section{Uji Sigifikansi Korelasi}

Uji t (uji koefisien regresi secara parsial)

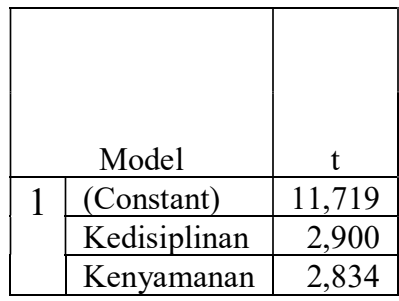

Pengaruh X1 terhadap Y

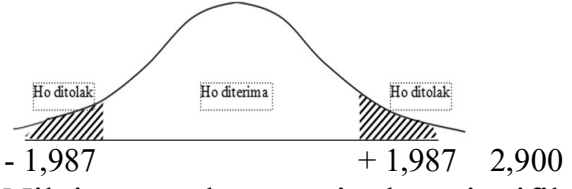

Nilai $\mathrm{t}$ table dengan tingkat signifikansi 0,05, dengan uji 2 sisi diperoleh hasil $\mathrm{t}_{\text {table }}=1,987 /-1,987$. Koefisien uji $\mathrm{t}$ Kedisiplinan nilanya 2,900 (2,900 > 1,987, Ho ditolak) yang berarti ada pengaruh kedisiplinan dengan hasil pembelajaran.

Pengaruh X2 terhadap Y

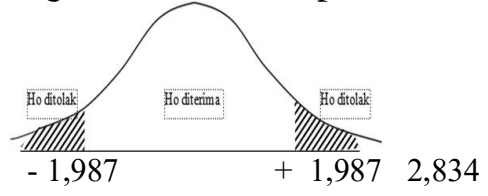

Sedangkan Kenyamanan koefisien uji t nilanya $2,834(1,987<2,834>-1,987$, Ho ditolak) berarti ada pengaruh kenyamanan dengan hasil pembelajaran.

\section{Uji F (uji koefisien regresi secara bersama-sama)}

ANOVA ${ }^{a}$

\begin{tabular}{|c|c|c|c|c|c|c|}
\hline \multicolumn{2}{|r|}{ Model } & $\begin{array}{c}\text { Sum } \\
\text { of } \\
\text { Square } \\
\text { s }\end{array}$ & $\begin{array}{l}d \\
f\end{array}$ & $\begin{array}{c}\text { Mea } \\
\text { n } \\
\text { Squa } \\
\text { re }\end{array}$ & $\mathrm{F}$ & Sig. \\
\hline \multirow[t]{3}{*}{1} & $\begin{array}{l}\text { Regress } \\
\text { ion }\end{array}$ & $\begin{array}{r}1218, \\
485\end{array}$ & 2 & $\begin{array}{r}609, \\
242\end{array}$ & $\begin{array}{r}8,7 \\
87\end{array}$ &, $000^{\mathrm{b}}$ \\
\hline & $\begin{array}{l}\text { Residu } \\
\text { al }\end{array}$ & $\begin{array}{r}6170 \\
819\end{array}$ & $\begin{array}{l}8 \\
9\end{array}$ & $\begin{array}{r}69,3 \\
35\end{array}$ & & \\
\hline & Total & $\begin{array}{r}7389, \\
304 \\
\end{array}$ & $\begin{array}{l}9 \\
1\end{array}$ & & & \\
\hline
\end{tabular}

Berdasarkan tabel di atas diperoleh $\mathrm{F}$ hitung sebesar 8,787.

F tabel dapat dilihat pada lampiran, dengan menggunakan tingkat signifikansi 0,05 , dengan df 1 (jumlah variabel -1$)$ atau 3-1 = 2, dan df 2 (n-k1) atau $92-2-1=89$. Hasil diperoleh untuk F tabel sebesar 3,10.

Kriteria pengujian

-Ho diterima bila nilai $\mathrm{F}$ hitung $\leq \mathrm{F}$ tabel 
- Ho ditolak bila nilai $\mathrm{F}_{\text {hitung }}>\mathrm{F}_{\text {tabel }}$

\section{Daerah Penentuan Ho pada Uji F}

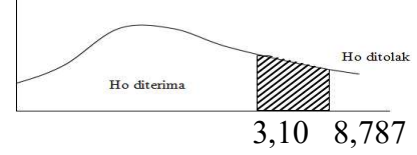

$\mathrm{Ha}: \mathrm{b}_{1}, \mathrm{~b}_{2}, \mathrm{~b}_{3}, \mathrm{~b}_{4} \neq 0$

Karena Nilai $\mathrm{F}$ hitung $>\mathrm{F}$ tabel $(8,787>$ 3,10), maka Ho ditolak. Sehingga hipotesis yang menyatakan bahwa terdapat pengaruh Kedisiplinan dan Kenyaman di asrama secara bersamasama terhadap Hasil pembelajaran taruna/ taruni angkatan 51 dan 52 Akpelni semarang dapat diterima dengan kata lain kedisiplinan dan kenyaman secara bersama-sama berpengaruh terhadap hasil pembelajaran.

\section{Analisis koefisien determinasi (Adjusted R Square) \\ Hasil analisis regresi ganda \\ Model Summary ${ }^{b}$

\begin{tabular}{|c|c|c|c|c|}
\hline & $\mathrm{R}$ & $\begin{array}{c}\mathrm{R} \\
\text { Squ } \\
\text { are }\end{array}$ & $\begin{array}{l}\text { Adj } \\
\text { uste } \\
\text { d R } \\
\text { Squ } \\
\text { are }\end{array}$ & $\begin{array}{l}\text { Std. Error of } \\
\text { the Estimate }\end{array}$ \\
\hline 1 & $\begin{array}{r}4 \\
06 \\
\text { a }\end{array}$ & $\begin{array}{r}0,16 \\
5\end{array}$ & $\begin{array}{r}0,14 \\
6\end{array}$ & 8,32677 \\
\hline
\end{tabular} \\ a. Predictors : (Constant), Kenyamanan Kedisiplinan \\ b. Dependent Variable : Hasil \\ Pembelajaran}

Dari hasil pengujian Hipotesis didapatkan bahwa nilai atau koefisien determinasi $\left(\mathrm{R}^{2}\right)$ sebesar 0,165. Nilai tersebut berarti $16,5 \%$ perubahan variabel Hasil Pembelajaran (Y) dapat diterangkan oleh Kedisiplinan $\left(\mathrm{X}_{1}\right)$ dan Kenyamanan di Asrama $\left(\mathrm{X}_{2}\right)$.
Faktor pendukung dan penghambat Kedisiplinan dalam meningkatakan Hasil pembelajaran.
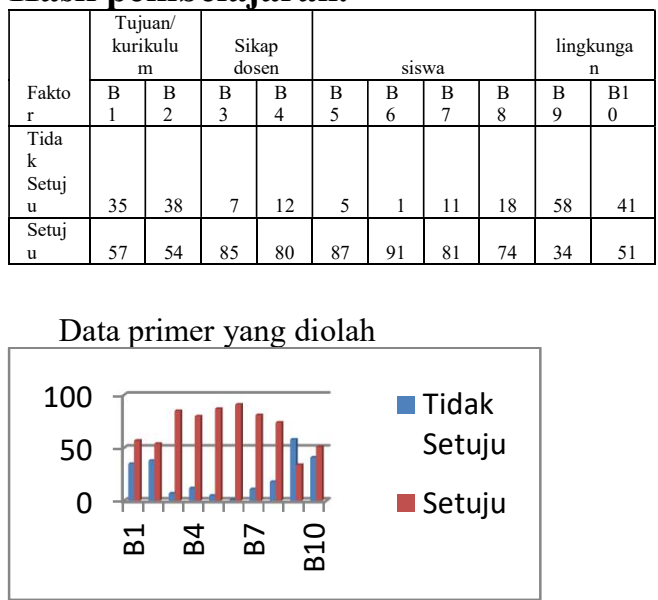

Dari grafik diatas dapat diketahui bahwa B1, B2 ( tujuan/ kurikulum) dan B9,B10 (lingkungan) nilainya tinggi diatas 30, berarti faktor tersebut merupakan penghambat kedisiplinan yang paling besar.

\section{PENUTUP}

\section{Kesimpulan}

Terdapat pengaruh positif dan signifikan Kedisiplinan terhadap Hasil pembelajaran taruna/ taruni angkatan 51 dan 52 Akpelni semarang, dengan $\mathrm{rx}_{1} \mathrm{y}=0,299 ; \mathrm{r} 2 \mathrm{x} 1 \mathrm{y}=0,09(9$ $\%$ ); dan thitung $=2,900$.

Terdapat pengaruh positif dan signifikan Kenyamanan di asrama terhadap Hasil pembelajaran taruna/ taruni angkatan 51 dan 52 Akpelni semarang, dengan $\mathrm{rx}_{2} \mathrm{y}=0,293 ; \mathrm{r}_{2} \mathrm{x}_{1} \mathrm{y}$ $=0,086(8,6 \%)$; dan $t_{\text {hitung }}=2,834$.

Faktor pendukung dan penghambat kedisiplinan dalam meningkatkan hasil pembelajaran adalah sebagai berikut :

1. Tujuan/ kurikulum

Kurikulum yang terlalu kaku, kurang fleksibel, terlalu dipaksakan, dapat menimbulkan perilaku ketidakdisiplinan, dalam proses 
belajar mengajar dan proses pendidikan. Kegiatan diluar jam kuliah yang berlebihan juga akan mengganggu kegiatan belajar berikutnya.

2. Lingkungan kampus

Kondisi kampus/ fasilitas di asrama yang kurang menyenangkan, kurang teratur, dan kurang memadai serta fasilitas pendukung IT dan belajar mengajar seperti komputer, HP dapat menyebabkan perilaku ketidakdisiplinan.

3. Siswa (Taruna/ taruni)

Taruna/ taruni memiliki potensi dan kepribadian yang berbeda-beda. Pemahaman terhadap masingmasing individu secara cermat dan tepat akan berpengaruh terhadap keberhasilanpenanaman kedisiplinan.

4. Sikap dosen

Dosen yang bersikap baik, penuh kasih sayang, dan berkompeten dalam penyampaian materi memungkinkan keberhasilan penanaman kedisplinan taruna/ taruni.

\section{Saran}

Berdasarkan hasil analisis, maka penulis memberikan beberapa saran :

a. Saran untuk penelitian selanjutnya. Penelitian ini memberikan informasi bahwa kedisiplinan dan kenyamanan di asrama berpengaruh terhadap hasil pembelajaran sebesar $16,5 \%$. Hal ini menunjukkan bahwa hasil pembelajaran masih banyak dipengaruhi oleh faktor lain. Oleh karena itu, diharapkan dalam penelitian selanjutnya untuk mengetahui faktor-faktor yang mempengaruhi hasil pembelajaran selain yang diteliti dalam penelitian ini, misalnya antara lain kematangan fisik, kelelahan, psikologi seperti bakat, minat, kecerdasan, dan motivasi.

b. Saran untuk taruna/ taruni.

Secara umum hasil pembelajaran taruna/ taruni dipengaruhi oleh beberapa faktor. Dalam penelitian ini dipengaruhi oleh faktor kedisiplinan dan kenyamanan di asrama. Untuk meningkatkan hasil pembelajaran, taruna/ taruni harus dapat menumbuhkan kedisiplinan dari kesadarannya sendiri agar dapat memacu semangat untuk melakukan kegiatan belajar sehingga hasil yang diperoleh dapat maksimal. Belajar hendaknya dilakukan secara terusmenerus dan menjadikannya suatu kebiasaan yang rutin. Perhatian taruna/ taruni terhadap mata kuliah itu sendiri pada saat perkuliahan berlangsung sebaiknya lebih ditingkatkan.

c. Saran untuk dosen

Para dosen sebaiknya berupaya untuk menumbuhkan dan meningkatkan kedisiplinan taruna/ taruni dan meminimalisir kekurangnyamanan di asrama sehingga dapat mencegah merosotnya hasil pembelajaran taruna/ taruni. Untuk meningkatkan kedisiplinan taruna/ taruni, dosen perlu memberikan pemahaman tentang disiplin dalam hal belajar dan memberikan pembinaan berkelanjutan yang menjadikan taruna/ taruni mempunyai kedisiplinan dalam dunia perkuliahan. Selain itu hendaknya dosen juga menciptakan suasana belajar mengajar yang menarik dan menyenangkan agar taruna/ taruni tidak merasa jenuh dan bosan. 
d. Saran untuk kampus

Untuk meningkatkan hasil pembelajaran kedepannya, diharapkan pihak kampus dapat memberikan sebuah apresiasi secara berkelanjutan bagi taruna/ taruni yang berprestasi baik dalam bidang akademik maupun non akademik serta memperbaiki dan melengkapi fasilitas di asrama agar semangat belajar dalam mencapai hasil pembelajaran yang diharapkan semakin meningkat dari tahun ke tahun dan menghasilkan lulusan yang berkompeten di bidangnya masing-masing.

\section{DAFTAR PUSTAKA}

Arikunto, Suharsimi. 2002. Prosedur Penelitian Suatu Pendekatan Praktek Edisi Revisi V . Jakarta: Rineka Cipta .

Bungin, Burhan. 2009. Metodologi penelitian Kuantitatif, Jakarta: Penerbit Kencana Prenada Media Grup

Depdiknas. 2005. Kamus besar bahasa Indonesia edisi ketiga Jakarta: Balai Pustaka.

Hadi, Sutrisno. 2000. Analisis Regresi . Yogyakarta: Andi Offset.

Keputusan Presiden Nomor 401981. 2007

Kamus Umum Bahasa Indonesia. Jakarta

Slameto. 2003. Belajar dan Faktor - Faktor Yang Mempengaruhinya Jakarta: Rineka Cipta.

Sudjana. 1996. Statistik. Bandung. Tarsito.

Sudjana, Nana. 2004. Penilaian Hasil Proses Belajar MengajaRBandung:PT. Remaja Rosdakarya.

Sutardjo. 2003. Belajar dan Pembelajaran . Jakarta: Balai
PustakaW.J.S Porwodarminto. 1976.

Suryabrata, Sumadi. 1998. Psikologi Pendidikan . Jakarta: Raja Grasindo Persada.

TIM Pengembangan MKDK IKIP SEMARANG. 1990. Psikologi Belajar. Semarang: IKIP Semarang Press

Tu'u, Tulus. 2004. Peran Disiplin Pada Perilaku dan Prestasi Siswa. Jakarta. Grasindo.

Baharuddin, Esa Nur Wahyuni. (2009). Teori Belajar \& Pembelajaran. Jogjakarta: Ar-Ruzz Media.

Bhuono Agung. (2005). Strategi Jitu Memilih Metode Statistik Penelitian dengan SPSS. Yogyakarta: Andi Offset.

Depdiknas (2003) Undang-Undang Sistem Pendidikan Nasional.

Hurlock, Elizabeth (2002) Perkembangan Anak . Jakarta: Erlangga

Mudrajad Kuncoro. (2003). Metode Riset Untuk Bisnis dan Ekonom: Bagaimana. Meneliti dan Menulis Tesis?. Jakarta : Erlangga.

Muhibbin Syah. (2008). Psikologi Pendidikan Dengan Pendekatan Baru. Bandung: Remaja Rosdakarya.

Devia Nur Fitriana. (2010). Pengaruh Lingkungan Teman Sebaya dan Motivasi Belajar Terhadap Prestasi Belajar Akuntansi Siswa Kelas X Program Keahlian Akuntansi SMK YPKK 2 Sleman Tahun Ajaran 2010/2011. Skripsi. Pendidikan Akuntansi FISE UNY.

Muslim Fikri. (2011). Pengaruh Motivasi Belajar dan Disiplin Belajar terhadap Prestasi Belajar Mahasiswa Jurusan

Kependidikan Islam Angkatan 
2007 dan 2008 Fakultas Skripsi. Fakultas Tarbiyah dan Tarbiyah dan Keguruan UIN Keguruan UIN Sunan Kalijaga Sunan Kalijaga Yogyakarta. Yogyakarta. 